\title{
Effect of Mortar Constraint Conditions on Pullout Behavior of GFRP Soil Nails
}

\author{
Zhi Chen, ${ }^{1}$ Mengke Que, ${ }^{1}$ Lifei Zheng $\mathbb{D},{ }^{2}$ Xiaoqinq Li $\mathbb{D},{ }^{2}$ and Yang Sun ${ }^{1}$ \\ ${ }^{1}$ School of Civil Engineering Architecture and Environment, Hubei University of Technology, Wuhan 430068, China \\ ${ }^{2}$ School of Civil Engineering and Mechanics, Huazhong University of Science and Technology, Wuhan 430074, China \\ Correspondence should be addressed to Xiaoqinq Li; lixiaoqing108@163.com
}

Received 25 September 2019; Revised 22 November 2019; Accepted 9 December 2019; Published 10 January 2020

Academic Editor: Michele Zappalorto

Copyright (c) 2020 Zhi Chen et al. This is an open access article distributed under the Creative Commons Attribution License, which permits unrestricted use, distribution, and reproduction in any medium, provided the original work is properly cited.

Glass fiber reinforced polymer (GFRP) bars are safe, light, and environmentally friendly and, hence, have emerged as desirable alternatives to traditional steel reinforcements in soil nailing wall reinforcement. The loads experienced by GFRP soil nails are transmitted through bonding with mortar and the surrounding soil mass. Constraints of the soil mass on mortar affect the pullout performance of the nails. This paper presents a laboratory test study on the influence of different mortar constraint conditions on the pullout behavior of GFRP soil nails. The results indicated that single loading or cyclic loading has a negligible effect on the failure modes of specimens under different constraints. Therefore, all specimens underwent the same mode of failure, i.e., splitting failure of the mortar. The ultimate pullout force associated with single loading under strong constraint conditions was $77 \%$ higher than that under unconstrained conditions, and the anchorage depth increased from $0.6 \mathrm{~m}$ to $1.0 \mathrm{~m}$. The load-slip curves obtained for unconstrained conditions and strong constraint conditions were approximately straight lines and double broken lines, respectively. The ultimate tensile stress of GFRP soil nails exceeds the tensile strength of ordinary steel bars, indicating that these nails have sufficient strength reserve.

\section{Introduction}

The soil nailing wall is a retaining structure for soil excavation and slope stability. Soil nails are in contact with the surrounding soil through the mortar along the length direction, and the strength and stiffness of the undisturbed soil are improved via the bonding frictional resistance on the contact surface. Glass fiber reinforced polymer (GFRP) is lightweight as well as easily designed and processed and has high strength, fatigue resistance, and corrosion resistance, thereby representing a reasonable alternative to steel reinforcements [1-4]. The supporting characteristic of a soil nailing wall is that the soil nail is mainly pulled in tension. The tensile strength of a GFRP bar is highly matched with the mechanical requirements of a soil nail, and hence, the material properties can be optimized for use of GFRP bars as soil nails [5-7].

In addition, GFRP soil nail is used to achieve soil stability through the interaction between the nails and soil. The pullout resistance of the nail is usually determined by means of indoor pullout tests and field pullout tests, which are the most important indicator of soil nail performance. The pullout performance of soil nails has been extensively investigated via experiments. For example, indoor tests focus mainly on the bond-slip characteristics of reinforced soil nails and mortar; several corresponding bond-slip models have been proposed [8-15]. Field tests are biased toward the study of the shear-displacement relationship between the soil nail and the soil interface. Correspondingly, various pullout models have been proposed $[5,16,17]$. Theoretical analysis has been performed on the pullout mechanism of GFRP bars. However, the effect of rock and soil mass constraint conditions on mortar-wrapped bars in actual engineering and their effects on the mechanism of GFRP soil nails have rarely been considered.

Zhu et al. used a fiber Bragg grating (FBG) strain sensor to monitor the strain of GFRP soil nails at different depths in an indoor pullout test [18]. Some impact parameters associated with the pullout characteristics of the nails were analyzed via numerical simulation and the hyperbolic model 
of stress-strain proposed by Milligan and Tei [19]. Zou et al. performed pullout tests on 20 GFRP anchors embedded in two different soil slopes to analyze the effects of mortar standing time (the period from hardening of cement slurry to application of drawing force), water-cement ratio, and other parameters [20]. The effects of different soil conditions on the pullout force were examined, and the results revealed that the surrounding rock constraint conditions have a significant influence on the pullout performance of the anchor. The local bond stress-slip response of GFRP tendons was investigated by Harajli et al., who considered concrete beam specimens and pullout specimens [21, 22]. In that work, the bond failure mode and bond strength of the steel bars and GFRP bars were compared by considering the length of the ribs, external thread form, and strength of the concrete. The bond strength of the GFRP rib is two to three times lower than that of the steel bar. Furthermore, the ACI440 specification is nonconservative in the experimental design of the GFRP bars. Gao et al. performed pullout tests on FRP anchors indoors and outdoors and discussed the slip equation of the bolts used for this type of material [23]. The authors also established the relationship among slip, bond stress, anchor length, and pullout force. Moreover, the authors proposed a reference formula for calculating the anchoring force of FRP anchors, the bond strength between fiber-reinforced plastic tie bar and cement slurry, and a design method for the bonded structure.

Owing to its low price, glass fiber is the most widely used fiber material in civil engineering. GFRP material has high strength, but its tensile modulus is about $1 / 4$ that of steel bar and undergoes a different deformation from that of the steel bar under load. Moreover, GFRP material is heterogeneous and nonisotropic, and hence, the theory for reinforced concrete nails can only be partly applied to analyze the pullout performance of these materials [24-26]. The soil mass on the soil nail has a certain restraining effect on the deformation of the mortar body, and the overburden pressure generated by this effect is related to the rock and soil conditions [27]. Theoretical upper and lower limits for the constraint conditions of mortar include the unconstrained condition (lower limit) and strong constraint condition (upper limit). This work was aimed at investigating (via laboratory tests) the effects of mortar constraint conditions on the pullout behavior of GFRP soil nails. The stress-strain distribution of GFRP soil nails along the length of the bar and the bond shear stress between the nails and the mortar were evaluated. The outcome of this investigation can be used to solve key technical problems encountered in GFRP anchoring support engineering applications.

\section{Materials and Methods}

\subsection{Material Properties}

2.1.1. GFRP Material. A polyethylene GFRP bar with a thread on the surface was selected as the test soil nail (see Table 1 for the material parameters). One end of the bar was wrapped with a galvanized iron pipe for fixing the anchor head of the canister-type jack.
2.1.2. Mortar and Other Materials. The pullout test was performed on the cement mortar specimens. The cement mortar raw materials were PO 42.5 cement, fine sand (particle size: $<2 \mathrm{~mm}$ ), and water. A flowing mixture of mortar (cement: sand : water $=1: 1.5: 0.4$ ) was used to make standard cube blocks for determining the axial compression strength $(40 \mathrm{MPa})$. The carbon fiber sheet (CFS) was selected in accordance with a technical code for safety appraisal of engineering structural strengthening materials (GB507282011). The material parameters of the CFS are shown in Table 2.

2.2. Test Plan. In this work, we considered two different mortar constraint conditions, and two different loading paths were employed for analyzing the anchoring performance of GFRP soil nails under mortar unconstrained and strong constraint conditions. The strain gauges were pasted at a distance of $10 \mathrm{~cm}$ along the length of the bar (see Figure 1 for the bonding mode of the gauge). Two strain gauges were pasted along the perimeter direction of the bar at each node.

Pullout specimens with sizes of $1000 \mathrm{~mm} \times 150 \mathrm{~mm} \times$ $150 \mathrm{~mm}$ were tested. The specimens were poured and maintained for 28 days, as shown in Figure 2. The high strength and high modulus properties of CFS can effectively restrain the structural deformation, and the structure bearing capacity can be significantly increased [28]. In this test, the untreated specimens and the specimens strengthened with the carbon fiber sheet were used to simulate the unconstrained conditions and the strong constraint conditions, respectively.

The strain gauge was pasted on the surface of the bar in order to obtain the strain distribution for every other $10 \mathrm{~cm}$ along the length of the bar. To reduce the influence of the strain gauge wire on the bond between CFS and specimen surface, the CFS (width: $10 \mathrm{~cm}$ ) was cut for reinforcing the circumferential direction of the pullout specimens. The wire was then removed from the gap of the CFS. The simulation of the strong constraint condition was performed as follows: paste a layer of carbon sheet in the three surfaces (two sides and bottom surface) without wire extraction along the length of the bar (longitudinal direction), and the adhesive is epoxy resin. Afterward, the specimen is strengthened with transverse CFS to ensure that each surface of the specimen is affixed with three layers of CFS. The method of reinforcement is shown in Figure 3.

2.3. Experimental Procedure. Two different loading modes are employed in this pullout test. Single loading: a multistage loading mode was adopted, and the load was increased by $5 \mathrm{kN}$ at each stage. After $2 \mathrm{~min}$ of stabilization, the corresponding tensile force value, strain value of each measurement point, and end elongation were recorded up to destruction of the specimen. Cyclic loading: a multistage loading mode was also adopted. Furthermore, a load of $10 \mathrm{kN}$ was applied in each stage until the peak of the corresponding cycle was reached. After 2 min of stabilization, 
TABLE 1: Parameters of GFRP bars.

Matrix (name/

characteristics)

Diameter (mm) Volume fraction (\%) Failure load (kN) Tensile strength (MPa) Elastic modulus (GPa)

Polyethylene/thermoplastic

25

68

295

601

39.9

TABLe 2: Parameters of CFS.

\begin{tabular}{lccc}
\hline Tensile strength $(\mathrm{MPa})$ & Tensile elasticity modulus $(\mathrm{MPa})$ & Elongation $(\%)$ & Mass per unit area $\left(\mathrm{g} / \mathrm{m}^{2}\right)$ \\
\hline$\geq 3400$ & $\geq 2.3 \times 105$ & $\geq 1.6$ & $\leq 300$ \\
\hline
\end{tabular}
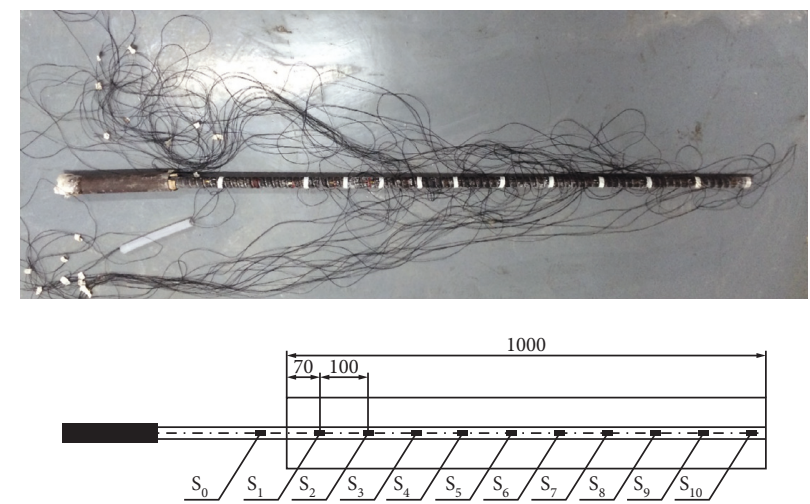

FIGURE 1: Strain gauge bonding image (unit: $\mathrm{mm}$ ).

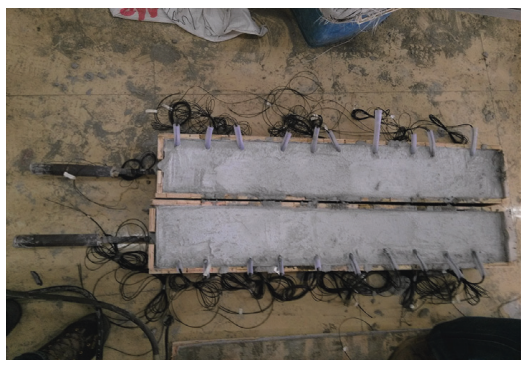

(a)

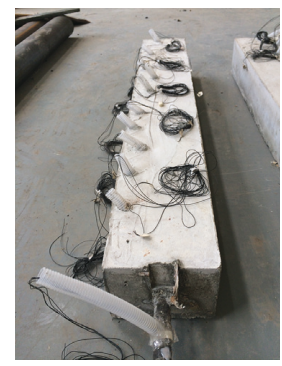

(b)

FIGURE 2: Specimens under unconstrained conditions.

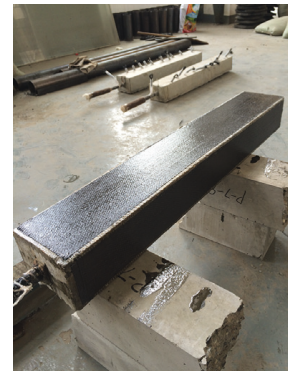

(a)

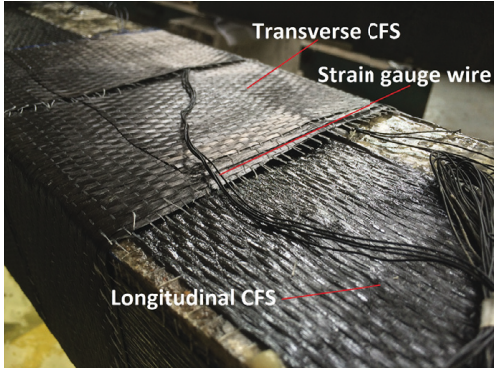

(b)

FIgURE 3: The manufacturing process of CFS.

the corresponding tensile force value, strain value of each measurement point, and end elongation were recorded, and the specimen was then unloaded.
The unconstrained test specimen undergoes the following cyclic process: $0 \longrightarrow 40 \longrightarrow 0 \longrightarrow 60 \longrightarrow 0$ $\longrightarrow 80 \longrightarrow 0 \longrightarrow$ destruction. Similarly, the strong 
constraint specimen undergoes the $0 \longrightarrow 60 \longrightarrow 0 \longrightarrow 100$ $\longrightarrow 0 \longrightarrow 140 \longrightarrow 0 \longrightarrow$ destruction cyclic process. The pullout test process is shown in Figure 4.

\section{Results and Discussion}

3.1. Failure Form of Pullout Specimen. The mechanical characteristics of the material and the spatial relationship among the bar, mortar, and surrounding rock in the pullout test are analyzed. The results indicate that the failure forms of the pullout test can be divided into the following four categories [29]: (1) fracture of bar body, owing to insufficient strength, (2) direct pullout of the bar due to lack of interface strength between the mortar and the bar, (3) splitting failure of the mortar, and (4) shear failure at the interface between the mortar and the rock mass, as a result of lack of interface bond strength.

As shown in Figure 5, under unconstrained conditions, both specimens undergo the same form of mortar splitting failure during the pullout test. The final failure mode of the specimen under single loading is shown in Figure 5(a). The ultimate tensile force is $114 \mathrm{kN}$. During the loading process, the GFRP bar changes only slightly, microcracks appear in the mortar in the later stage of the loading, and then continuous loading leads to instantaneous splitting. Furthermore, the cracks penetrate the middle of the mortar top surface. The final failure mode of the specimen under cyclic loading is shown in Figure 5(b). The ultimate tensile force is $106 \mathrm{kN}$. In the $0 \longrightarrow 40$ and $0 \longrightarrow 60$ cycle process, the specimen changes only slightly. In the $0 \longrightarrow 80$ cycle process, after the load exceeds $70 \mathrm{kN}$, a slight cracking sound (without considerable cracking) is emitted from the mortar surface in contact with the jack. In the final destruction cycle process, cracks form near the jack and propagate to the other end and also appear in the middle of the mortar top surface.

The criterion for the end of the test under the condition of strong constraint is that when the specimen experiences a certain load, the sudden sound of violent cracking determines the failure of the specimen. Both specimens undergo the same form of splitting failure (see Figure 6). After the test, a crack running from the bar to the top surface appears on the contact surface between the specimen and the jack. The CFS on the top surface is then removed, and the through cracks on the top surface of the specimen can be observed distinctly. During the removal process, the CFS is partially separated from the mortar on the top surface, owing to the extraction position of the strain gauge wire on the top surface of the specimen.

Figure 6(a) shows the final failure mode after a single loading process. As the figure shows, the crack forms in the center of the top surface and the ultimate tensile force is $202 \mathrm{kN}$. During the loading process, when the pulling force reaches $120 \mathrm{kN}$, a slight sound of mortar crushing on the contact surface between the jack and the mortar is heard. As the load increases, the specimen and the jack emit a crisp sound associated with the damage. When the ultimate pullout force is reached, a very loud cracking sound is suddenly emitted from the specimen. The final failure mode of cyclic loading is shown in Figure 6(b). The difference

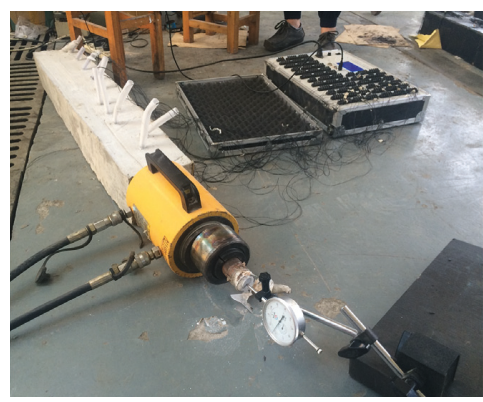

(a)

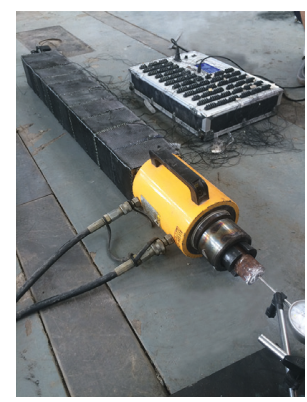

(b)
FIgURe 4: Pullout test under two types of constraint conditions: (a) unconstrained condition; (b) strong constraint condition.

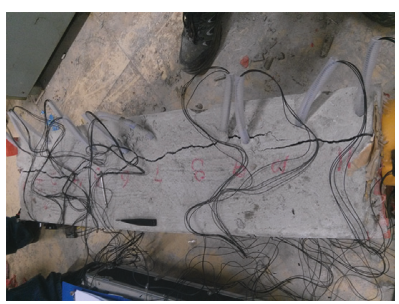

(a)

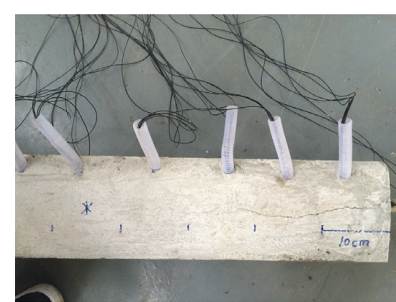

(b)
Figure 5: Pullout tests under unconstrained conditions: (a) failure mode under single loading; (b) failure mode under cyclic loading.

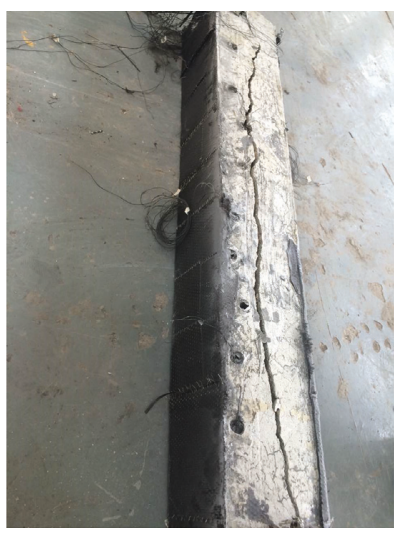

(a)

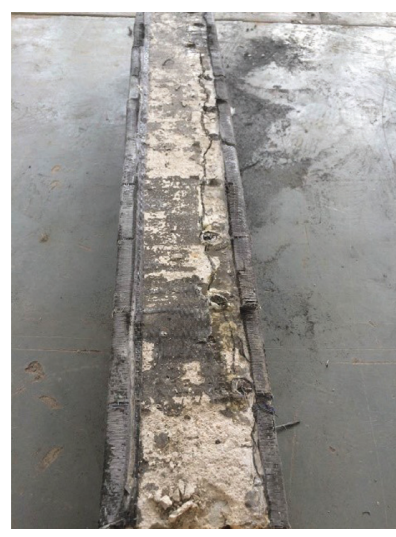

(b)
FIgURe 6: Pullout test under strong constraint condition: (a) failure mode under single load; (b) failure mode under cyclic loading.

results from the mortar crack located at the edge of the specimen top surface where the lead-out hole of the strain gauge wire is connected. The corresponding ultimate pullout force is $190 \mathrm{kN}$. In the $0 \longrightarrow 60 \mathrm{kN}$ loading stage, the specimen changes only slightly; in the later cyclic loading stages $(0 \longrightarrow 100 \mathrm{kN}$ and $0 \longrightarrow 140 \mathrm{kN})$, the specimen emits a clear and brittle cracking sound; when loaded to $190 \mathrm{kN}$, the specimen emits a sudden cracking sound and is then destroyed.

Each specimen has a square cross section; hence, the top surface experiences the weakest constraint, and the middle 
position of the top surface is the closest to the bar. Therefore, when fracture occurs, the crack should form in the middle position, as verified by the failure of the unconstrained specimens.

A comparison of the cracks formed in the single and cyclic loading specimens revealed that the cracks in the cyclic loading specimen are formed at the edge of the top surface. The wire lead-out hole lowers the bearing capacity of the cross section near the strain gauge. Therefore, the developed cracks penetrate the holes, indicating that the cyclic loading contributes significantly to the development of internal cracks.

\subsection{Strain Distribution}

3.2.1. Single Loading Test. Figures 7 and 8 show the strain distribution along the bar length of samples subjected to single loading under unconstrained conditions and strong constraint conditions.

Variations in the strain of each measurement point in Figures 7 and 8 reveal that, under both constraints, the strain value decreases along the anchorage depth of the bar. Efficient anchorage depths of $0.6 \mathrm{~m}$ and $1.0 \mathrm{~m}$ at final failure are obtained for unconstrained conditions and strong constraint conditions, respectively. The strain value of point $\mathrm{S} 1$ is the largest, and the points after the effective anchorage depth are small and almost unchanged. For a given mortar ratio and specimen size, the depth of strain transmission is related to the load and the constraint conditions. When the load is increased, the strain of the bar is transferred to the deep part of the specimen. Table 3 shows the depth of strain transmission under the two constraint conditions. In terms of strain attenuation, the degree of attenuation occurring under the unconstrained condition is considerably greater than that occurring under the strong constraint condition. For example, during loading to $100 \mathrm{kN}$, the former decreases from $5332 \mu \varepsilon$ at point $S 1$ to $43 \mu \varepsilon$ at point S6, while the latter decreases from $5563 \mu \varepsilon$ at point S1 to $148 \mu \varepsilon$ at point S8.

The strain transfer depth is measured by strain gauges bonded to the surface of the bar. During the loading process, the strain of the bar is transferred from the loading end to the opposite end, and there exists a zero-strain position nearest from the loading end. The distance from the certain position to the loading end is determined as the strain transfer depth. The test strain transfer depth is used to reflect the anchorage depth of the bar. The ultimate pullout force and anchorage depth are the important capability parameters [30]. The restraint conditions have a significant effect on them. Under single loading, the ultimate pullout force of the strong constraint condition specimen is $77 \%$ higher than that of the unconstrained condition, and the anchorage depth increases from $0.6 \mathrm{~m}$ to $1.0 \mathrm{~m}$.

3.2.2. Cycle Loading Test. Figure 9 shows the variations in the strain of measurement points from S0 to S5 under unconstrained conditions. The dotted lines in the figure represent the boundaries of cycle loading. Similarly, with the increase in load, the strain value of each point increases. The

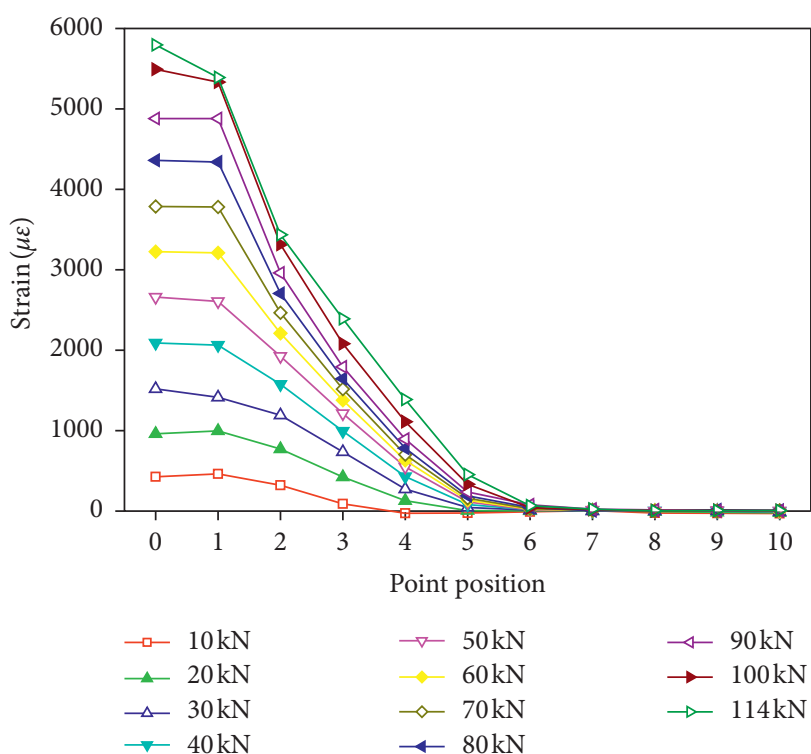

FIGURE 7: Single-load strain curves of GFRP bars under unconstrained conditions.

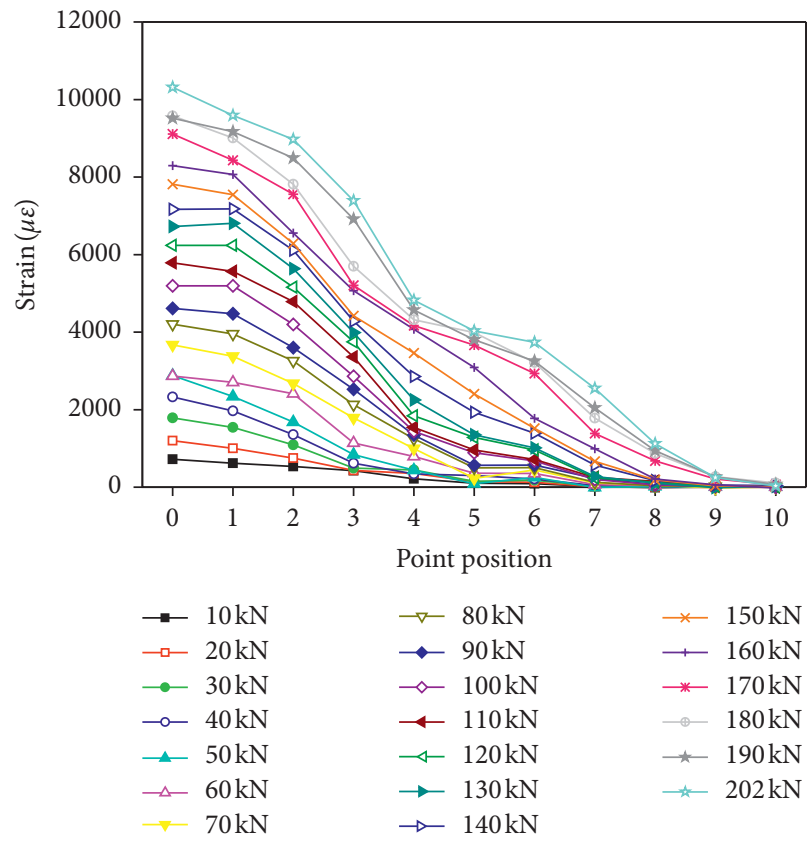

FIGURE 8: Single-load strain curves of GFRP bars under strong constraint conditions.

strain attenuation begins at point S2 along the anchorage depth of the bar. The strain value of points after S5 is small and almost unchanged, thereby the efficient anchorage depths are $0.5-0.6 \mathrm{~m}$. In the process of 4 times of cycle loading, there is almost no residual strain, and the whole cycle presents linear elastic. In the last cycle, the strain curve of measurement point $S 1$ is approximately parallel to the S0, which indicates that the mortar at the end of S1 has little restraint effect on the GFRP bar.

Figure 10 shows the variations in the strain of measurement points from S0 to S9 under strong constraint 
TABLE 3: Strain transfer depth under different constraint conditions.

\begin{tabular}{lccc}
\hline Constraint condition & Load $(\mathrm{kN})$ & Strain transfer depth $(\mathrm{m})$ & Remarks \\
\hline \multirow{2}{*}{ Unconstraint } & 40 & 0.5 & Effective anchorage depth \\
\hline & 114 & 0.6 & 0.5 \\
Strong constraint & 50 & 0.8 & \\
& 110 & 0.9 & Effective anchorage depth \\
\hline
\end{tabular}

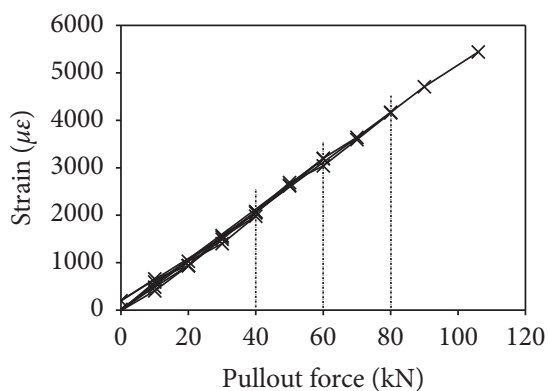

$*$ So

(a)

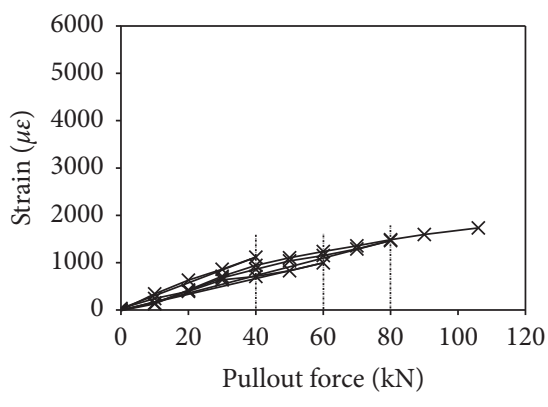

$* \mathrm{~S} 3$

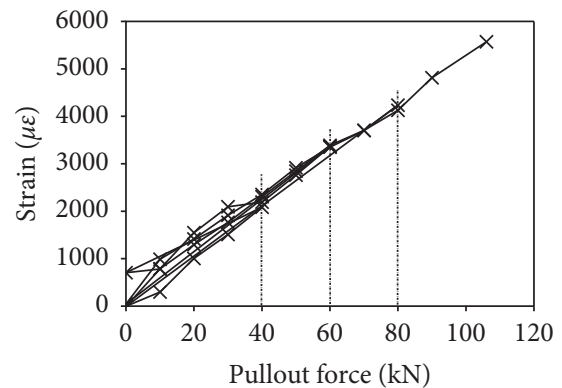

$* \mathrm{~S} 1$

(b)

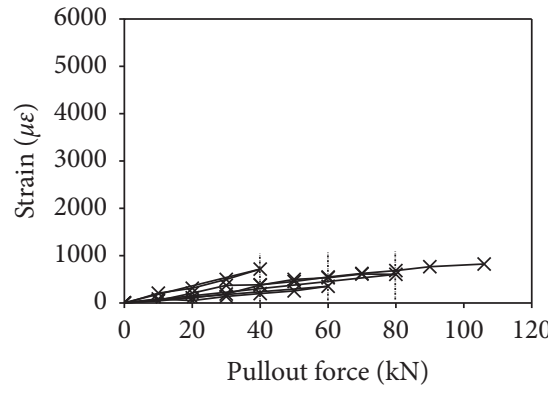

$*$ S4

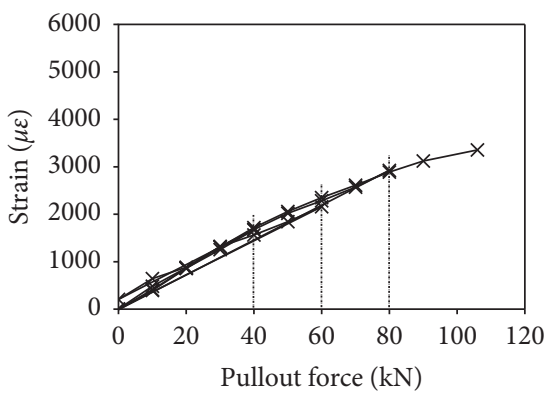

$*$ S2

(c)

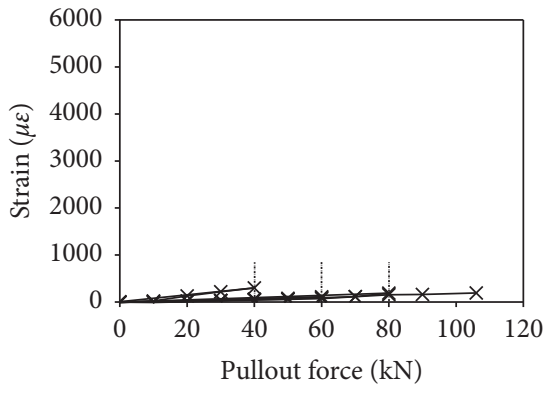

$*$ S5

(d)

(e)

(f)

FIgURE 9: Cycle-load strain curves of GFRP bars under unconstrained conditions.

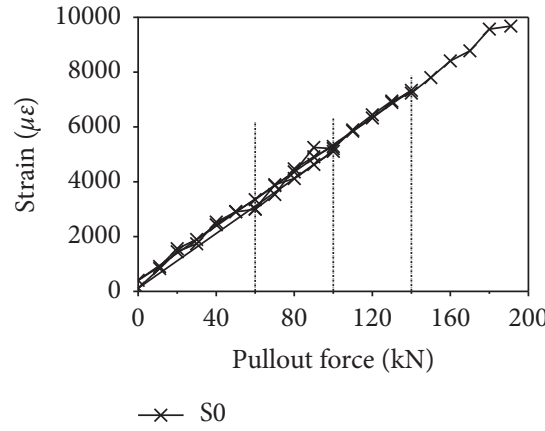

(a)

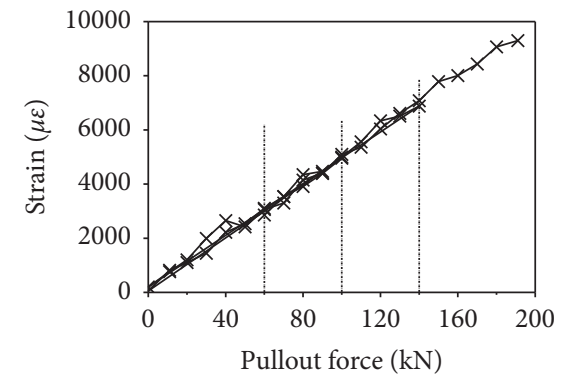

$* \mathrm{~S} 1$

Figure 10: Continued. 


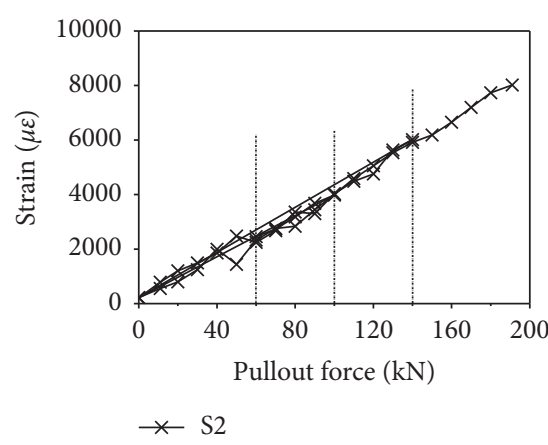

(c)

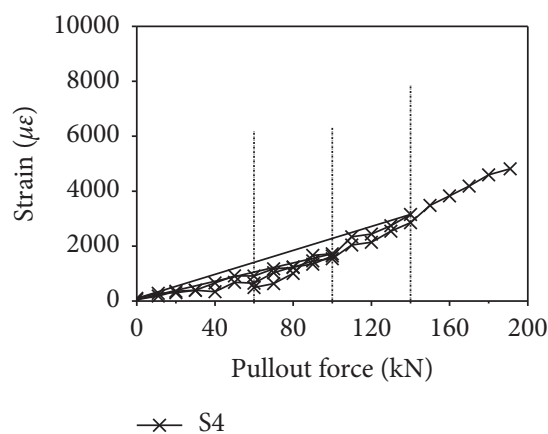

(e)

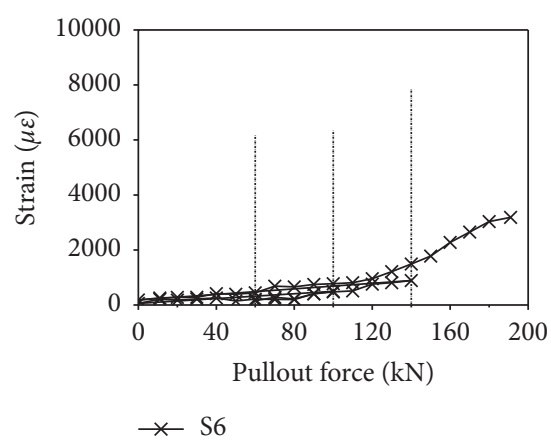

(g)

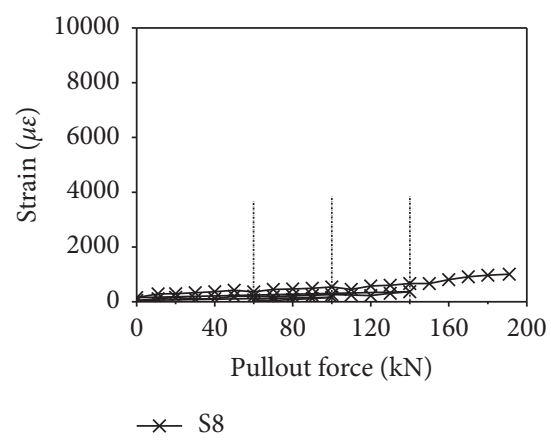

(i)

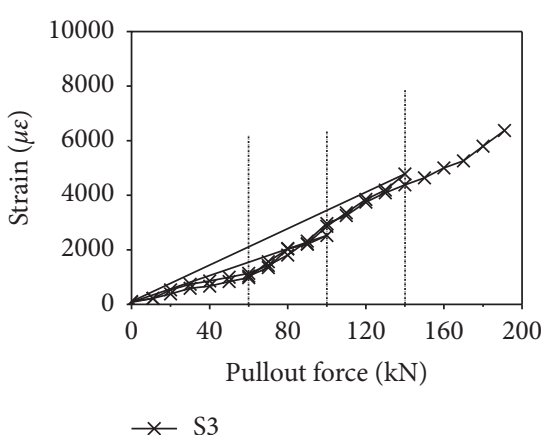

(d)

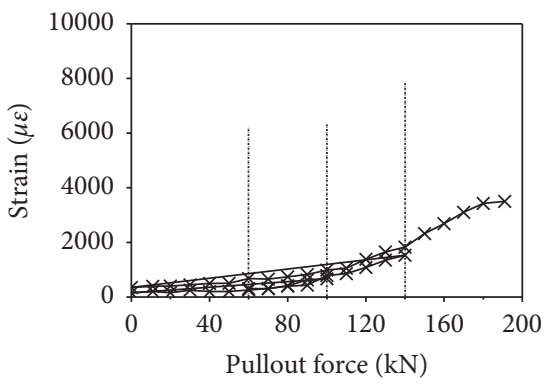

$\leftarrow$ S5

(f)

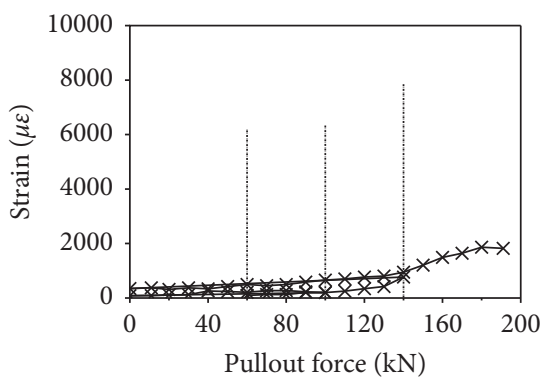

$*$ S7

(h)

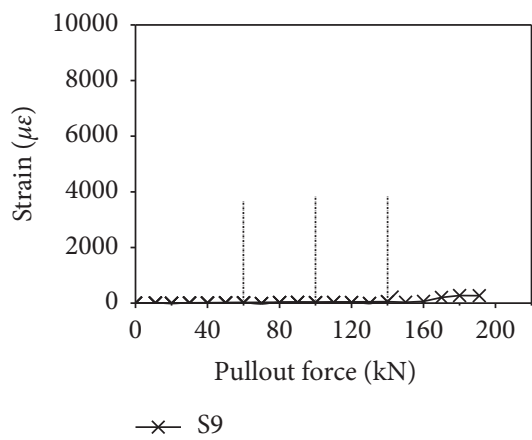

(j)

FIGURE 10: Cycle-load strain curves of GFRP bars under strong constraint conditions.

conditions. In the first three cyclic loading, the strain change of each point is similar to unconstrained conditions, mainly concentrated at the loading end. In the last cyclic loading, the strain of the bar is transferred to the point S9. Unlike unconstrained conditions, the strain attenuation begins at point S4. Generally, the strain distribution is similar under two different loading modes of single and cycle loading. 
3.3. Shear Stress Distribution. The axial force of each point can be calculated from the strain value at the corresponding measurement point:

$$
N_{i}=\frac{\pi}{4} D^{2} E \varepsilon_{i}
$$

where $N_{i}$ denotes the axial force at a calculation point and $\varepsilon_{i}$ denotes the strain value at a calculation point $(i=1,2, \ldots, 10)$. And, $E$ and $D$ denote the elastic modulus and diameter of the GFRP bar, respectively.

The average shear stress at each point $\left(\tau_{i}\right)$ can be calculated as the ratio of the change in the axial force $(\Delta N)$ of the GFRP bar and the contact area $(A)$ between the bar and the mortar:

$$
\tau_{i}=\frac{\Delta N}{A}=\frac{N_{i-1}-N_{i}}{\pi D L} .
$$

The contact area $(A)$ is the product of the circumference $(\pi D)$ of the bar and the distance $(L)$ between the two calculated points.

Figure 11 shows the distribution of the shear stress along the length of the bar subjected to single loading. As shown in the figure, the peak of the shear stress between the bar and the mortar occurs 0.1-0.2 m away from the loading end. The peak value increases with increasing magnitude of the pullout force. When the force reaches $100 \mathrm{kN}$, the maximum shear stress is $5.05 \mathrm{MPa}$, and the shear stress value decreases to $0 \mathrm{kN}$ at a depth of $0.6-0.7 \mathrm{~m}$. The peak value decreases, and the shear stress is transferred to the deep part of the specimen, when the force exceeds $100 \mathrm{kN}$; that is, once the shear stress peak value has decreased, the specimen may be damaged, thereby reflecting the characteristics of brittle failure under unconstrained conditions.

Figure 12 shows the irregular distribution of the shear stress generated along the length of the bar subjected to single loading under strong constrained conditions. In the early stage of loading, the shear stress peak appears at a distance of 0.1-0.2 $\mathrm{m}$ from the loading end. When the pullout force exceeds $140 \mathrm{kN}$, the peak is gradually transferred to the deep part. When the failure load is reached, a stress peak of 6.42 MPa occurs $0.4 \mathrm{~m}$ away from the loading end. Consider the shear stress between the bar and the mortar. This stress can be transmitted $0.7 \mathrm{~m}$ away from the loading end, when the pullout force exceeds $100 \mathrm{kN}$. However, when the force is $<100 \mathrm{kN}$, this stress is transmitted to the end of the bar and increases gradually. In the later stage of loading, the peak value of the shear stress drops sharply and then increases, owing possibly to the shear failure of the mortar. The load is then transmitted to the end of the specimen.

3.4. Load-Slip Characteristics. The measured elongation of the bar consists of the three main components: the elastic elongation corresponding to the exposed part of the bar, bond slip between the bar and mortar, and elastic deformation of the mortar. The area of the mortar cross section is considerably larger than that of the bar cross section, and the force is mainly transmitted to the mortar layer through the shear stress. Therefore, the mortar undergoes negligible

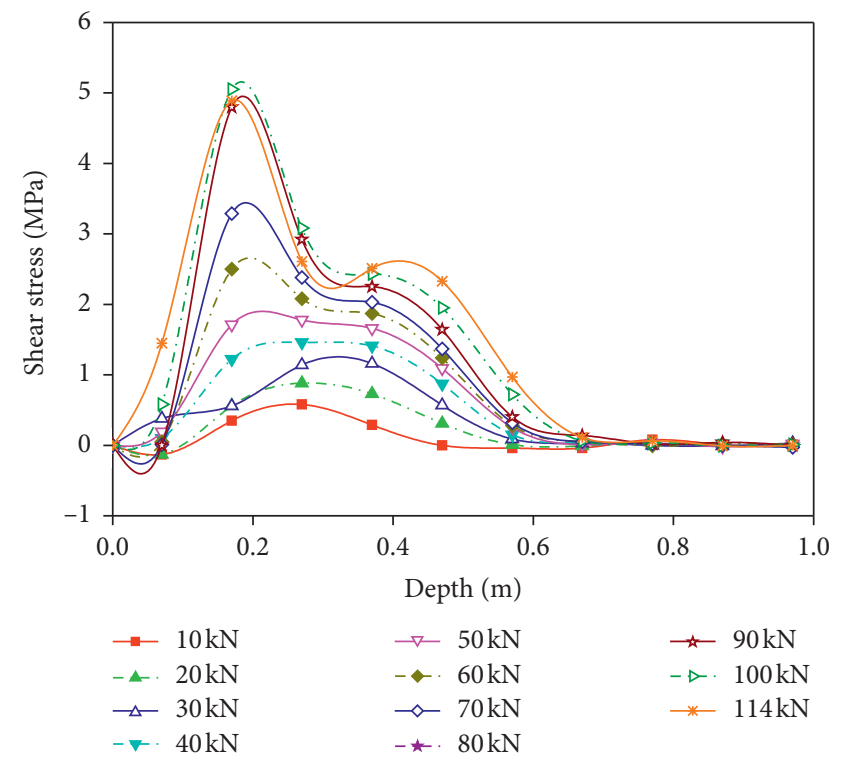

FIGURE 11: Single load shear stress curves obtained along the length of samples under unconstrained conditions.

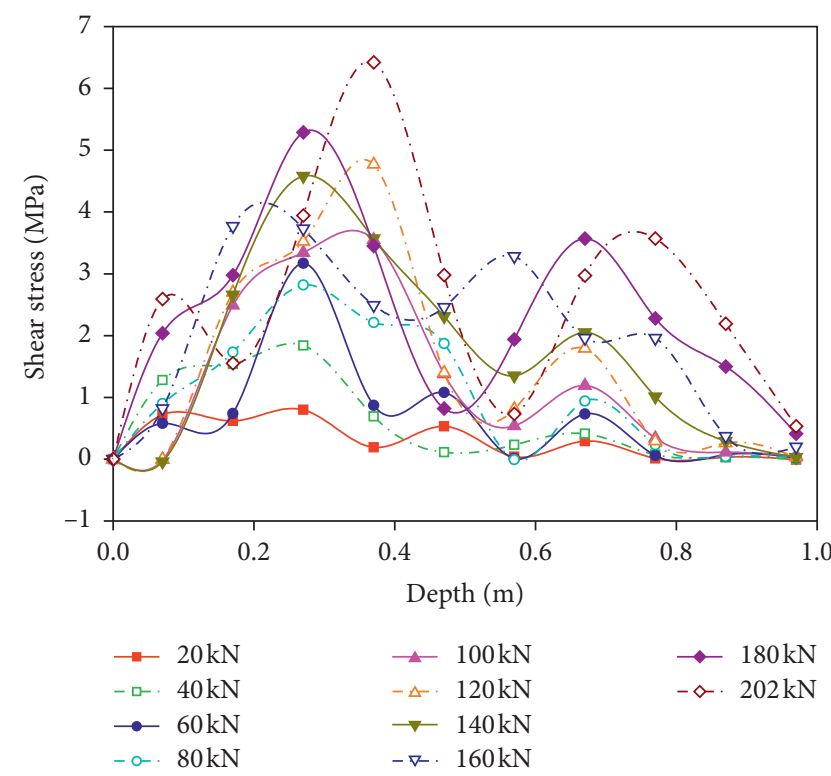

Figure 12: Single load shear stress curves obtained along the length of samples under strong constraint conditions.

deformation. The magnitude of the bond slip can be calculated as follows:

$$
\delta_{s}=\delta_{0}-\delta_{f}
$$

where $\delta_{0}$ is the elongation measured by a dial indicator, $\delta_{f}$ is the free end elongation of the GFRP bar, and $\delta_{s}$ is the bond slip between the bar and the mortar.

The load-slip curve obtained for a single load test performed under two constraint conditions is shown in Figure 13. An approximately linear curve is obtained under unconstrained conditions, as shown in the figure. When the pullout force is increased to $100 \mathrm{kN}$, an inflection point 


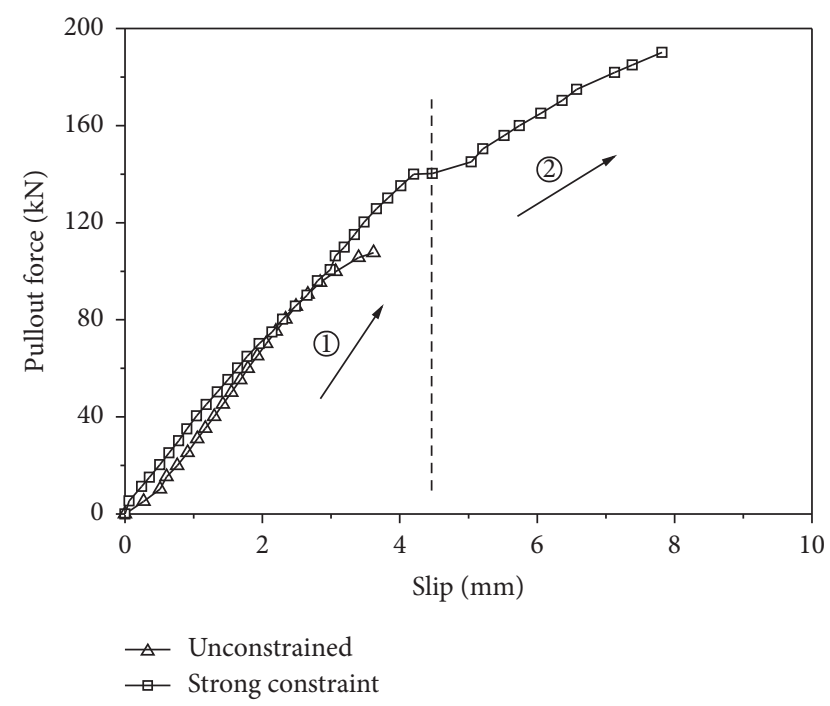

FIGURE 13: Single load-slip curves corresponding to two types of constraint conditions.

occurs, and the specimen is then rapidly destroyed (ultimate slip amount: $3.62 \mathrm{~mm}$ ). Consistent with the double broken line model, a load-slip curve consisting of two main regimes is obtained under strong constraint conditions. An inflection point occurs at $130 \mathrm{kN}$, and the curve is approximately linear in stage (1). The slope of the curve decreases after this point, and the final slip amount is $7.82 \mathrm{~mm}$. The shear stress increases with increasing pullout force, and the shear stress of the mortar at the loading end reaches the bond strength first. When the pullout force increases to the inflection point of the curve, this indicates that the mortar at the loading end is damaged via shear failure. Furthermore, the maximum shear stress in stage (2) is transferred to the deep part. Part of the damaged mortar (in contrast to the unconstrained specimen) can also be loaded under strong constraint conditions.

In the unconstrained pullout test, the slip increment in the early stage of loading is larger than the increment associated with the strong constraint condition; that is, the chemical bonding force and mechanical biting force between the mortar and the soil nail are greater under strong constraint conditions (than under unconstrained conditions). These strong forces result in limited relative displacement between the nail and mortar. Numerical simulation was carried out for the pullout test of FRP bars in rock mass by Zheng and Dai [13], and the results of the load-slip curve were between the two constraints in this test. It is verified that the theoretical upper and lower limits of the mortar constraints in this test include the unconstrained condition (lower limit) and strong constraint condition (upper limit). The crack penetrates the mortar at a load of $200 \mathrm{kN}$, which is converted to a tensile stress of $407 \mathrm{MPa}$ on the section of the GFRP bar. The tensile strength of the GFRP bar is higher than that of an ordinary steel bar, indicating that the bar has sufficient strength reserve for soil nailing.

Figure 14 shows the load-slip curves of cyclic loading performed under unconstrained conditions. Similar curves are obtained for the first three cycles, where

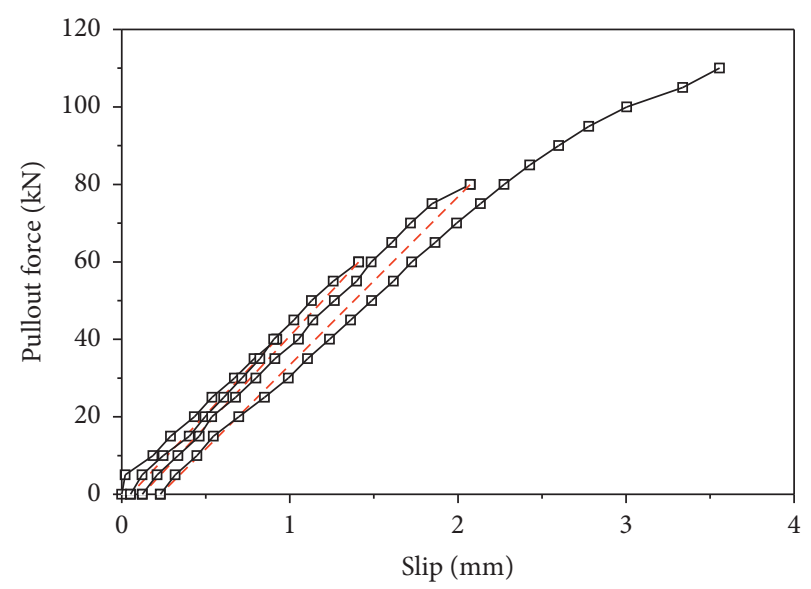

FIGURE 14: Cyclic load-slip curves obtained under unconstrained conditions.

$0 \longrightarrow 40 \longrightarrow 0 \longrightarrow 60 \longrightarrow 0 \longrightarrow 80 \mathrm{kN}$, unloading leads to low residual deformation, and the curves are relatively linear. Unloading after loading to $80 \mathrm{kN}$ yields a residual slip of $0.3 \mathrm{~mm}$. During the last loading $(105 \mathrm{kN})$, a slip of $3.56 \mathrm{~mm}$ is generated, and the specimen is destroyed.

Figure 15 shows the load-slip curves obtained for cyclic loading under strong constraint conditions. In the first three loading processes, the slip changes linearly until a load of $140 \mathrm{kN}$ is reached, where an inflection point occurs. The characteristics of the single loading stage are the same as those of the last loading stage, where an inflection point is also observed. Similarly, linear variation intervals occur for stage (1) and stage (2) of the single load condition, and the final slip amount is $9.43 \mathrm{~mm}$.

A comparison of the four bond slip curves reveals that the slip characteristics of the GFRP bar and the mortar are only modestly affected by the loading form. Moreover, the slip amount varies approximately linearly with the load. The final slip amount of the unconstrained condition associated with different loading modes changes only slightly. However, the final slip amount associated with the strong constraint condition under cyclic loading increases from $7.82 \mathrm{~mm}$ to $9.43 \mathrm{~mm}$.

Consider the slip at the end of the specimen and the failure characteristics, under the unconstrained condition. The analysis results reveal that cracks form and penetrate the entire specimen when the tension stress is increased to the shear strength of the mortar. This results in destruction of the entire specimen, which is only subjected to stage (1) under strongly constrained conditions. Upon entering stage (2) of the slip curves, cracks occur at the loading end and are gradually transferred to the deep part of the specimen. Due to the constrained condition, the mortar undergoes limited deformation. The frictional resistance between the mortar and the GFRP bar at the crack position and the mechanical biting force are maintained. This retards crack development, as validated by changes in the shear stress peak (Figure 11). The shear stress transmitted to the other end of the GFRP bar leads to an increase in slip, and progression rate of stage (2) decreases. 


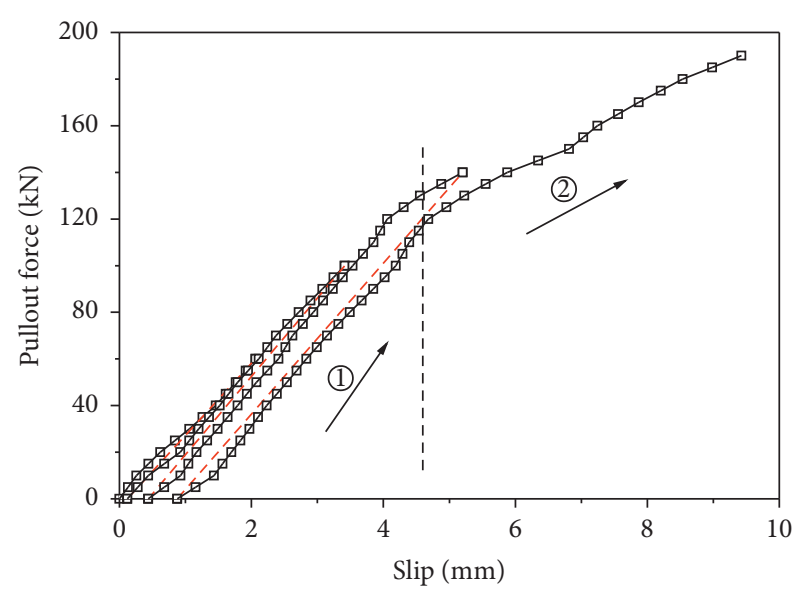

Figure 15: Cyclic load-slip curves obtained under strong constraint conditions.

\section{Conclusions}

This paper has presented the results of a laboratory study on the pullout behavior of GFRP soil nails under unconstrained conditions and strong constraint conditions of the mortar. The conclusions based on these results are summarized as follows:

(1) The specimen undergoes similar ultimate failure, i.e., splitting failure of the mortar, under the two types of constraint condition of the mortar. The ultimate pullout force is reduced under the cyclic loading, and the crack develops perfectly.

(2) Under the single-loading condition, the constraint condition of the mortar has a significant influence on the pullout force. Under the strong constraint condition, the ultimate pullout force is $77 \%$ higher than that of the unconstrained condition, and the anchoring depth increases from $0.6 \mathrm{~m}$ to $1.0 \mathrm{~m}$. The cyclic loading condition under two different confinement conditions leads to almost no residual strain, and the entire cycling process results in linear elastic changes. The effect of the load under the strong constraint condition can be transmitted more deeply along the bar than that under the unconstrained condition.

(3) Under the unconstrained condition, the peak shear stress between the bar and the mortar occurs at 0.1 $0.2 \mathrm{~m}$ from the loading end. This stress increases with increasing pullout force. A decrease in the shear stress peak indicates the failure and brittle failure characteristics of the specimen. Under the strong constraint condition, the shear stress distribution is irregular. The peak shear stress occurs near the loading end during the early stage of loading. With increasing pullout force, the peak shear stress is gradually transferred to the deep part of the bar.

(4) The load-slip curve is linear under unconstrained conditions and can be described by a double broken line model under strong constraint conditions. Part of the damaged mortar can also be loaded under strong constraint conditions. At specimen failure, the ultimate tensile stress of the GFRP bar is $407 \mathrm{MPa}$, which is higher than that of an ordinary steel bar, indicating that the GFRP bar has sufficient strength reserve for soil nailing.

\section{Data Availability}

The data used to support the findings of this study are included within the article.

\section{Conflicts of Interest}

The authors declare that there are no conflicts of interest regarding the publication of this paper.

\section{Acknowledgments}

This research was funded by the Science and Technology Project of Wuhan Urban and Rural Construction Bureau (Grant no. 201934), Hubei Province Technological Innovation Key Project (Grant no. 2018ACA134), and Youth Science and Technology Research Program of Hubei Education Department (Grant no. Q20181405).

\section{References}

[1] D.-W. Seo, K.-T. Park, Y.-J. You, and S.-Y. Lee, "Experimental investigation for tensile performance of GFRP-steel hybridized rebar," Advances in Materials Science and Engineering, vol. 2016, Article ID 9401427, 12 pages, 2016.

[2] D. Ellis, H. Tabatabai, and A. Nabizadeh, "Residual tensile strength and bond properties of GFRP bars after exposure to elevated temperatures," Materials, vol. 11, no. 3, p. 346, 2018.

[3] Y. M. Cheng, Y.-k. Choi, A. T. Yeung et al., "New soil nail material-pilot study of grouted GFRP pipe nails in Korea and Hong Kong," Journal of Materials in Civil Engineering, vol. 21, no. 3, pp. 93-102, 2009.

[4] M. Bazli, H. Ashrafi, A. Jafari, X. L. Zhao, R. K. S. Raman, and Y. Bai, "Effect of fibers configuration and thickness on tensile behavior of GFRP laminates exposed to harsh environment," Polymers, vol. 11, no. 9, p. 1401, 2019.

[5] H.-H. Zhu, J.-H. Yin, A. T. Yeung, and W. Jin, "Field pullout testing and performance evaluation of GFRP soil nails," Journal of Geotechnical and Geoenvironmental Engineering, vol. 137, no. 7, pp. 633-642, 2011.

[6] J. S. Yuan and M. N. S. Hadi, "Bond-slip behaviour between GFRP I-section and concrete," Composites Part B: Engineering, vol. 130, pp. 76-89, 2017.

[7] J.-J. Zheng and J.-G. Dai, "Prediction of the nonlinear pull-out response of FRP ground anchors using an analytical transfer matrix method," Engineering Structures, vol. 81, pp. 377-385, 2014.

[8] O. Gooranorimi, W. Suaris, and A. Nanni, "A model for the bond-slip of a GFRP bar in concrete," Engineering Structures, vol. 146, pp. 34-42, 2017.

[9] M.-y. Zhang, Z. Kuang, X.-y. Bai, and X.-y. Chen, "Pullout behavior of GFRP anti-floating anchor based on the FBG sensor technology," Mathematical Problems in Engineering, vol. 2018, Article ID 6424791, 10 pages, 2018. 
[10] X. Z. Lu, J. G. Teng, L. P. Ye, and J. J. Jiang, "Bond-slip models for FRP sheets/plates bonded to concrete," Engineering Structures, vol. 27, no. 6, pp. 920-937, 2005.

[11] D.-Y. Yoo, K.-Y. Kwon, J.-J. Park, and Y.-S. Yoon, "Local bond-slip response of GFRP rebar in ultra-high-performance fiber-reinforced concrete," Composite Structures, vol. 120, pp. 53-64, 2015.

[12] Y.-F. Wu and X.-M. Zhao, "Unified bond stress-slip model for reinforced concrete," Journal of Structural Engineering, vol. 139, no. 11, pp. 1951-1962, 2013.

[13] J.-J. Zheng and J.-G. Dai, "Analytical solution for the fullrange pull-out behavior of FRP ground anchors," Construction and Building Materials, vol. 58, pp. 129-137, 2014.

[14] F. Al-Mahmoud, A. Castel, R. François, and C. Tourneur, "Effect of surface pre-conditioning on bond of carbon fibre reinforced polymer rods to concrete," Cement and Concrete Composites, vol. 29, no. 9, pp. 677-689, 2007.

[15] Y.-W. Zhou, Y.-F. Wu, and Y. Yun, "Analytical modeling of the bond-slip relationship at FRP-concrete interfaces for adhesively-bonded joints," Composites Part B: Engineering, vol. 41, no. 6, pp. 423-433, 2010.

[16] L. D. Lorenzis, A. Rizzo, and A. L. Tegola, "A modified pullout test for bond of near-surface mounted FRP rods in concrete," Composites Part B: Engineering, vol. 33, no. 8, pp. 589-603, 2002.

[17] H. Jia, "Shear theoretical analysis on soil-nail interaction," Journal of Engineering Geology, vol. 10, no. 2, pp. 156-159, 2002.

[18] H. H. Zhu, C. C. Zhang, H. F. Pei, Y. Zhou, and B. Shi, "Pullout mechanism of GFRP soil nails," Chinese Journal of Geotechnical Engineering, vol. 34, no. 10, pp. 1843-1849, 2012, in Chinese.

[19] G. W. E. Milligan and K. Tei, "The pull-out resistance of model soil nails," Soils And Foundations, vol. 38, no. 2, pp. 179-190, 1998.

[20] W. L. Zou, Z. Wang, and C. H. Chen, "Field pull-out tests and failure model of GFRP screw anchors used to stabilize canal slopes of expansive soils," Chinese Journal of Geotechnical Engineering, vol. 31, no. 6, pp. 970-974, 2009, in Chinese.

[21] M. Harajli and M. Abouniaj, "Bond performance of GFRP bars in tension: experimental evaluation and assessment of ACI 440 guidelines," Journal of Composites for Construction, vol. 14, no. 6, pp. 659-668, 2010.

[22] M. H. Harajli, M. Hout, and W. Jalkh, "Local bond stress-slip relationship of reinforcing bars embedded in fiber reinforced concrete," ACI Materials Journal, vol. 92, no. 4, pp. 343-354, 1995.

[23] D. Y. Gao, H. T. Zhu, and J. J. Xie, "Applications of fiber reinforced plastic (FRP) bolts," Chinese Journal of Rock Mechanics and Engineering, vol. 23, no. 13, pp. 2205-2210, 2004, in Chinese.

[24] I. Vilanova, M. Baena, L. Torres, and C. Barris, "Experimental study of bond-slip of GFRP bars in concrete under sustained loads," Composites Part B: Engineering, vol. 74, pp. 42-52, 2015.

[25] M. Rezazadeh and V. Carvelli, "A damage model for highcycle fatigue behavior of bond between FRP bar and concrete," International Journal of Fatigue, vol. 111, pp. 101-111, 2018.

[26] G. Li, J. Zhao, and Z. Wang, "Fatigue behavior of glass fiberreinforced polymer bars after elevated temperatures exposure," Materials, vol. 11, no. 6, p. 1028, 2018.

[27] H. C. Biscaia, C. Chastre, and M. A. G. Silva, "Bond-slip model for FRP-to-concrete bonded joints under external compression," Composites Part B: Engineering, vol. 80, pp. 246-259, 2015.

[28] Y.-G. Cao, Y.-F. Wu, and X.-Q. Li, "Unified model for evaluating ultimate strain of FRP confined concrete based on energy method," Construction and Building Materials, vol. 103, pp. 23-35, 2016.

[29] E. Gudonis, R. Kacianauskas, V. Gribniak, A. Weber, R. Jakubovskis, and G. Kaklauskas, "Mechanical properties of the bond between GFRP reinforcing bars and concrete," Mechanics of Composite Materials, vol. 50, no. 4, pp. 457-466, 2014.

[30] F. Focacci, A. Nanni, and C. E. Bakis, "Local bond-slip relationship for FRP reinforcement in concrete," Journal of Composites for Construction, vol. 4, no. 1, pp. 24-31, 2000. 


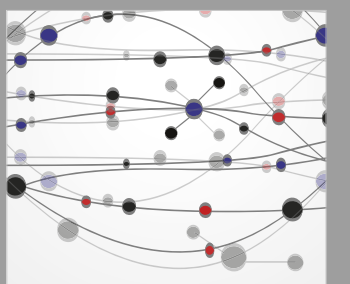

The Scientific World Journal
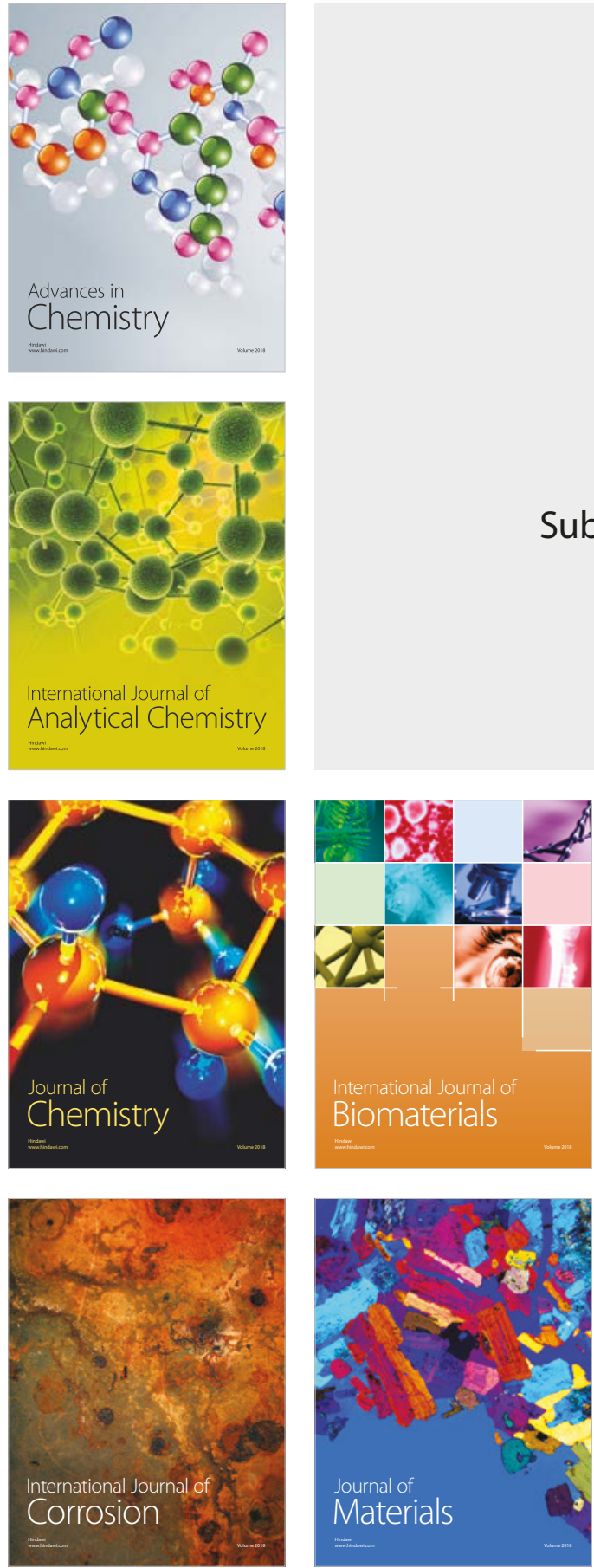

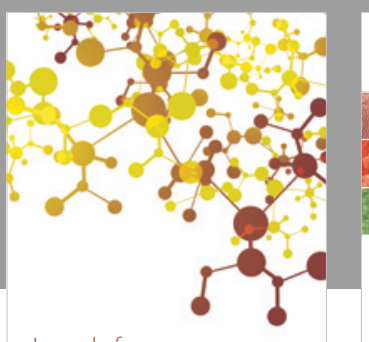

Journal of

Applied Chemistry
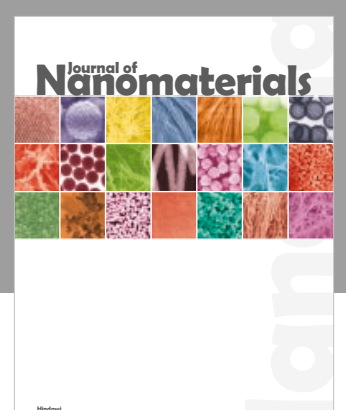

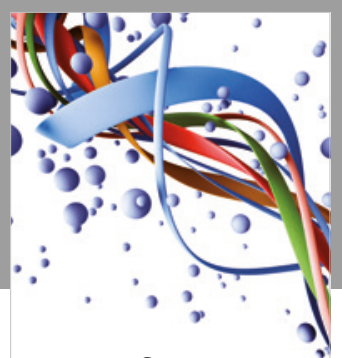

Scientifica

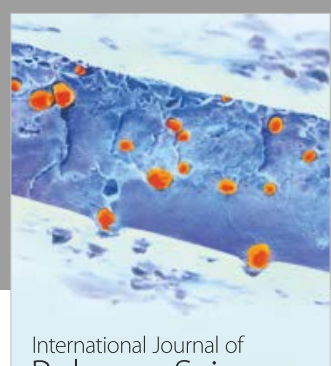

Polymer Science

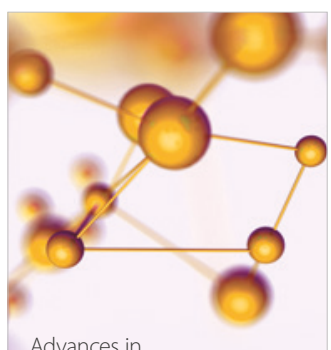

Physical Chemistry
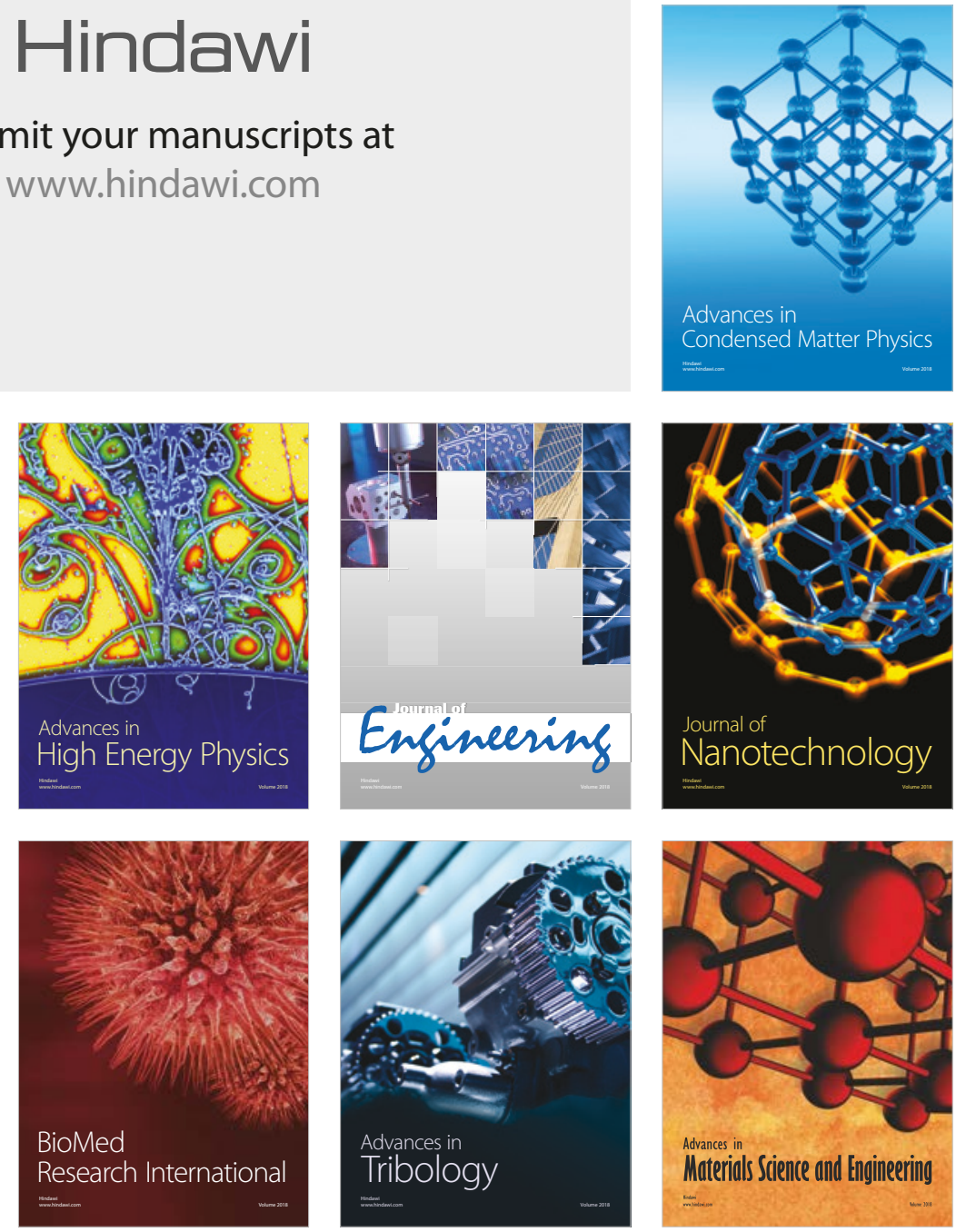